\section{Low back pain}

\section{Chiropractic manipulation is superior}

EdrroR,- - J R Jenner and M Barry state that "the most effective method [of spinal manipulation] is unknown, but physiotherapists, chiropractors, and osteopaths, who use a variety of techniques, all seem effective." ${ }^{\prime}$ This is not true. The benchmark study by Meade et al showed that spinal manipulation performed by a chiropractor was more effective for low back pain than manipulation performed by a physiotherapist. ${ }^{2}$ More importantly, the selection of the most suitable candidates for spinal manipulation is at least as important an indicator of the outcome as the technique that is applied. ${ }^{3}$ Not all randomly selected patients with low back pain require spinal manipulation.

The authors also state that "pathology in organs in the posterior part of the abdominal cavity may refer pain to the back-for example, aortic aneurysm or enlarged lymph nodes." In over 40 years of practising spinal manipulation one of us (PB) did not see any patient who presented with low back pain secondary to an aortic aneurysm or enlarged lymph nodes but did see many patients with prostatic disease, metastases to the spine, a retroflexed uterus, or kidney disease who presented with low back pain.

Physical Medicine and Rehabilitation,

PHILIP BRIEN

Newark, NJ,

USA

Retired dire

St Clares Riverside Medical Center,

MICHAEL J BRIEN Attending physiatrist

Denville, NJ,

1 Jenner JR, Barry M. ABC of rheumatology: low back pain. $B M \mathcal{F}$ 1995;310:929-32. (8 April.)

2 Meade TW, Dyer S, Browne W, Townsend J, Frank AO.

Low back pain of mechanical origin: randomised comparison of chiropractic and hospital outpatient treatment. BMF 1990 of chiropractic

3 Brien P, Brien MJ. Manipulative therapy and physiotherapy fo persistent back and neck complaints. $B M Y$ 1992;304:1309-11.

\section{Pain clinics have an important role}

EdrToR,-J $R$ Jenner and $M$ Barry give the impression that patients with low back pain are referred to pain clinics for a limited number of injections, for which the success rate is low. ${ }^{1}$ They fail to mention the much wider facilities, both diagnostic and therapeutic, available in pain clinics

\section{Advice to authors}

We prefer short letters that relate to a recently published article and we are unlikely to publish letters longer than 400 words and containing over five references. Letters may be shortened. Your letters should be typed with double spacing and include a word count. All authors need to sign the letter and provide one current appointment and address. We encourage you to declare any conflict of interest. Please enclose a stamped addressed envelope if you require an acknowledgment. or to pain management services and that the possibility of helping patients with chronic low back pain by a variety of techniques has improved the outlook for patients.

The authors also seem to be unaware that many of the behavioural and other rehabilitation pro grammes are based on interdisciplinary pain management services. While other specialties, including rehabilitation medicine, physiotherapy, occupational therapy, and clinical psychology, have major roles in these programmes, the pain management service is often responsible for their organisation. Such skill is available on a relatively widespread and national basis, and it is a pity that those who write in national journals seem to be unaware of facilities that have been available for many years.

KEITH BUDD

Mornington Clinic,

Bradford BD8 7HQ

1 Jenner JR, Barry M. ABC of rheumatology: low back pain. BM 1995;310:929-32. (8 April.)

\section{Occupational physicians and ergonomists should have a role}

EdrToR,-R M Ellis fails to mention work (especially in those workplaces where even the most simple of ergonomic practices do not exist) as an important cause of back pain among people who are employed..$^{1-3}$ This omission is made doubly worse by Ellis's advice that doctors "should see maintaining the person in employment as their priority." Unless the principles behind the Manual Handling Operations Regulations 1992 apply in the workplace, returning to work too soon may have the opposite effect.

Ellis mentions the "consultant led team" providing services focused on the "active management of back pain." Two other specialists should be added to the list-namely, occupational physicians and ergonomists.

D SEN

Merseyside and Cheshire Area Office,

Employment medical

Mealth and Safety Executive,

Bealth

Merseyside L20 3PG

1 Ellis RM. Back pain. BMF 1995;310:1220. (13 May.)

2 Clinical Standards Advisory Group. Epidemiology review: the epidemiology and cost of back pain. London: HMSO, 1994.

3 Health and Safety Executive. Self-reported work-related illness. Sudbury, Suffolk: HSE Books, 1993. (Research paper 33.)

4 Health and Safety Executive. Manual handling. Guidance on regulations. London: HMSO, 1992

\section{Specialist provision is inadequate}

EDrTOR,-R M Ellis clearly outlines the practical implications ${ }^{1}$ of the recommendations of the report on back pain by the Clinical Standards Advisory Group. ${ }^{2}$ If, however, a revolution is to be brought about in the early management of back pain then a radical change in current practice will be required. Appropriate and timely interventions allowing rapid referral to specifically designated back pain clinics after six weeks of continuing symptoms will require special funding and specific planning for staffing.

Specialist provision in Britain is already inadequate. $A$ recent survey found that the average wait for a new outpatient orthopaedic appointment was 24 weeks, ${ }^{3}$ and it has been calculated that the Calman report's recommendations for a consultant led service would necessitate a doubling of the current number of surgeons to 2000 simply to maintain the status quo.

A similar picture emerges for rheumatologists, with fewer than 300 full time equivalent consultants in Britain, or one per 230000 population. ${ }^{4}$ Musculoskeletal physicians, with their specialised knowledge of back care, ${ }^{5}$ are represented in the NHS by only four consultants and about six hospital specialists.

The government has no plans for extra funding of services, so it will fall to purchasers and providers to set up new patterns of care. The cost of providing back care to a general practice of 10000 patients is about $£ 88000$ a year, and already some fundholders are finding that employing their own specialists and physical therapists is cost effective.

It is essential that changes are adequately monitored, as no one yet has the perfect solution for clinical care. District based consultants, who would also support integrated primary care and provide appropriate secondary services, are clearly needed.

The Clinical Standards Advisory Group intends to publish a review after three years. I hope that there will be some worthwhile developments to report.

ADAM A WARD

Tunbridge Wells,

Kent TN2 5LF

1 Ellis RM. Back pain. BMๆ 1995;310:1220. (13 May.)

2 Clinical Standards Advisory Group. Back pain. Report by CSAG committee on back pain. London: HMSO, 1994.

3 British Orthopaedic Association. Consultant staffing requirements for an orthopaedic service in the National Health Service. London: BOA, 1995.

4 Mowat A. Musculoskeletal problems. Practitioner 1994;238:201. 5 British Institute of Musculoskeletal Medicine. The "specialist" in musculoskeletal medicine. Northwood, Middlesex: BIMM, 1995.

\section{Proposals of population solutions are beset by lack of knowledge}

EDITOR,-R M Ellis's editorial on back pain ${ }^{1}$ does not dig deeply enough into the assumptions underlying the report by the Clinical Standards Advisory Group. ${ }^{2}$ The report makes important recommendations, based largely on evidence from research, on the clinical management of patients with acute back pain. It also champions an integrated back pain service. Back pain, however, is a public health problem that is unlikely to be resolved by simple clinical measures in individual patients. Proposals of population solutions to the problem of back pain are beset by a lack of knowledge. ${ }^{3}$ How should a costly epidemic of a medical diagnosis be controlled when the causes of the condition and of the epidemic are poorly understood, the nature of the condition is debated, virtually no primary preventive measures have been shown to work, and "carrying on normal activities" (that is, no treatment) may be among the best treatments available?

Archie Cochrane sat on the United Kingdom Working Party on Back Pain, which reported in 1979 that "unfortunately there is insufficient basis at the moment for formulating advice that could be incorporated into health education directed at the prevention of back pain." Fifteen years on, this conclusion remains substantially unmodified, although Cochrane might have welcomed the fact 